\title{
REVALORACIÓN HISTÓRICA DEL PATRIMONIO. LA PLAZA DE ACHO A MEDIADOS DEL SIGLO XVIII ${ }^{[*]}$
}

\author{
REVALUATION OF HISTORICAL HERITAGE. THE ACHO SQUARE MID-18TH CENTURY
}

\author{
HENRY BARRERA CAMARENA ${ }^{(\star)}$ \\ Fecha de recepción: 25 mayo de 2015 \\ Fecha de aprobación: 06 de junio de 2015
}

\section{RESUMEN}

En el presente artículo se plantea revalorar el papel de la Plaza Firme de Toros de Acho como patrimonio histórico nacional, mediante el análisis de su importancia histórica, resaltando el rol que jugó en la reforma urbana borbónica de mediados del siglo XVIII y el tipo de arquitectura de su edificación. Con ello, se busca poner de relieve la trascendencia de uno de los cosos más antiguos del mundo, así como la necesidad que existe de ponerlo en valor, pese a los cambios morfológicos que ha sufrido hasta el presente. Tomando esto en consideración, el artículo se centrará exclusivamente en el estudio de la edificación, sin participar del acalorado debate actual respecto a la prohibición de las corridas de toros, pues, más allá del mismo, está en juego la conservación de un vestigio monumental que necesita ser recuperado y reinsertado a la rica historia de la ciudad de Lima.

\section{PALABRAS CLAVE}

Patrimonio histórico, reforma urbana, estilo arquitectónico

\begin{abstract}
In the present article, we propose the reassessment of the role of the Plaza Firme de Toros de Acho as national heritage by analyzing its historical significance, highlighting the role it played during the Bourbon urban reform in the mid 18th century and the type of architecture of its buildings. Thus, we seek to emphasize the transcendence of one of the oldest bullrings in the world and the urgency that there is for its revaluation, despite the morphological changes that it may have suffered in the time being. Considering this, the article will focus on the study of the building itself, without participating on the heated debate that currently takes place regarding the ban of bullfights, because, beyond it, is the conservation of a monumental relic that needs to be recovered and reinserted into the rich history of the city of Lima.
\end{abstract}

\section{KEYWORDS}

Historical, urban reform, architectural style

$\left(^{*}\right)$ Este artículo es una versión del cuarto capítulo del proyecto de investigación de tesis de pregrado para optar por el grado de licenciado en Historia por la Universidad Nacional Mayor de San Marcos. Se agradece los comentarios dados por la licenciada Milagros Romero a la versión preliminar del presente trabajo.

$\left.{ }^{* *}\right)$ Bachiller en Historia por la Universidad Nacional Mayor de San Marcos. Actualmente, cursa la maestría en Gestión del Patrimonio Cultural en la misma casa de estudios. Interesado en la investigación de inmuebles históricos del período colonial y republicano. Ha publicado artículos elaborados desde una perspectiva histórica y patrimonial. Contacto: henrybarrera20@gmail.com 
En 2016 la Plaza de Acho cumplirá 250 años de existencia, desde que se proyectó construir un espacio que albergue las corridas de toros callejeras durante el período colonial. A puertas de esta trascendental fecha, resulta contradictorio que el estado actual en que se encuentra no guarde relación con la rica historia, y tradición que sobre sus gradas y pasadizos se esconden.

En el año 1967, por solicitud del presidente del Consejo Nacional de Conservación y Restauración de Monumentos Históricos y Artísticos, en el Congreso de la República, se erogó la Resolución Suprema 922, la cual declaraba la Plaza de Acho Monumento Nacional, por mantener a pesar del tiempo su característico aspecto y ambiente tradicional desde 1766. A pesar de las distintas modificaciones arquitectónicas que se realizaron desde su fundación, aún conserva partes de su estructura original. Posteriormente, el ahora Ministerio de Cultura clasifica a la Plaza de Acho dentro de la categoría de monumento del tipo 'arquitectura civil pública'.

Según la investigadora Françoise Choay, para que un monumento adquiera su carácter histórico, "se tiene que producir un cierto distanciamiento capaz de generar una mirada sobre el pasado como tiempo diferente a aquel desde el cual se contempla" (2000, p. 126). Depende de cada sociedad el proteger u olvidar su patrimonio. Mientras mayor es el grado de afecto, espiritualidad y sentido de pertenencia que se siente respecto del patrimonio, las personas tienden a cuidarlo y revalorarlo como suyo. Si sucede lo contrario, si el patrimonio genera desdén, falta de compromiso cultural y es causa de despilfarro económico, está destinado a caer en el olvido y perder el sentido por el que fue nombrado como tal en primer lugar. A partir de lo propuesto por el especialista José Castillo Ruiz, quien afirma que "el Patrimonio Histórico es el conjunto de bienes materiales e inmateriales relacionados con la actividad del hombre a lo largo de la historia, los cuales disponen de significados para los ciudadanos en el presente, lo que exige su protección" (2007, p.14), en el presente trabajo se busca revalorar históricamente la Plaza de Acho, destacando el papel que jugó dentro de la sociedad en que fue planificada. En base a lo propuesto en el artículo siete de la Carta de Venecia de 1964 , que sostiene que el monumento es inseparable de la historia de la cual es testigo y del lugar en que está ubicado, es necesario devolverle a la plaza el vínculo estrecho que mantuvo con el desarrollo urbano de Lima en aquellos años.

\section{Importancia Histórica de la Plaza Firme de Toros}

Luego del fuerte impacto de la conquista y colonización de América, los españoles se encargaron de imponer a la población aborigen su estilo de vida, religión, forma de gobierno y, por supuesto, sus costumbres y creencias. De ese modo, introdujeron la corrida de toros, que rápidamente caló en el sentir de toda la población y que, con el pasar de los años, se convertiría en parte de la identidad de la sociedad limeña de tiempos coloniales. No obstante, al carecer de un coso que las pudiese albergar, constantemente se realizaban corridas a diferentes horas y en distintos ámbitos de la ciudad, lo cual generaba desazón, bullicio, intranquilidad y desorden. Estos factores también jugaron un rol en el proyecto de edificar el monumento arquitectónico.

La afición limeña tuvo que esperar, hasta mediados del siglo XVIII, para maravillarse ante la presencia de una Plaza de Toros. Entonces, el hacendado de Cañete Agustín Hipólito de Landaburu y Rivera propuso al virrey Manuel de Amat y Junient construir un local para las lidias de toros. Así, el 28 de junio, por medio de un superior decreto, el virrey aprobó y celebró el contrato con Agustín de Landaburu para la fabricación de una plaza firme1.

1. Archivo Central de la Beneficencia Pública de Lima (ACBPL). Documento empastado. Testimonio de la escritura de contrata, otorgada por los oficiales reales de la caja de corte con el señor Agustín Hipólito Landaburu en 28 de junio de 1765, ante Bernardino Méndez de Zúñiga. Este documento ha sido ya tratado por diversos investigadores. 


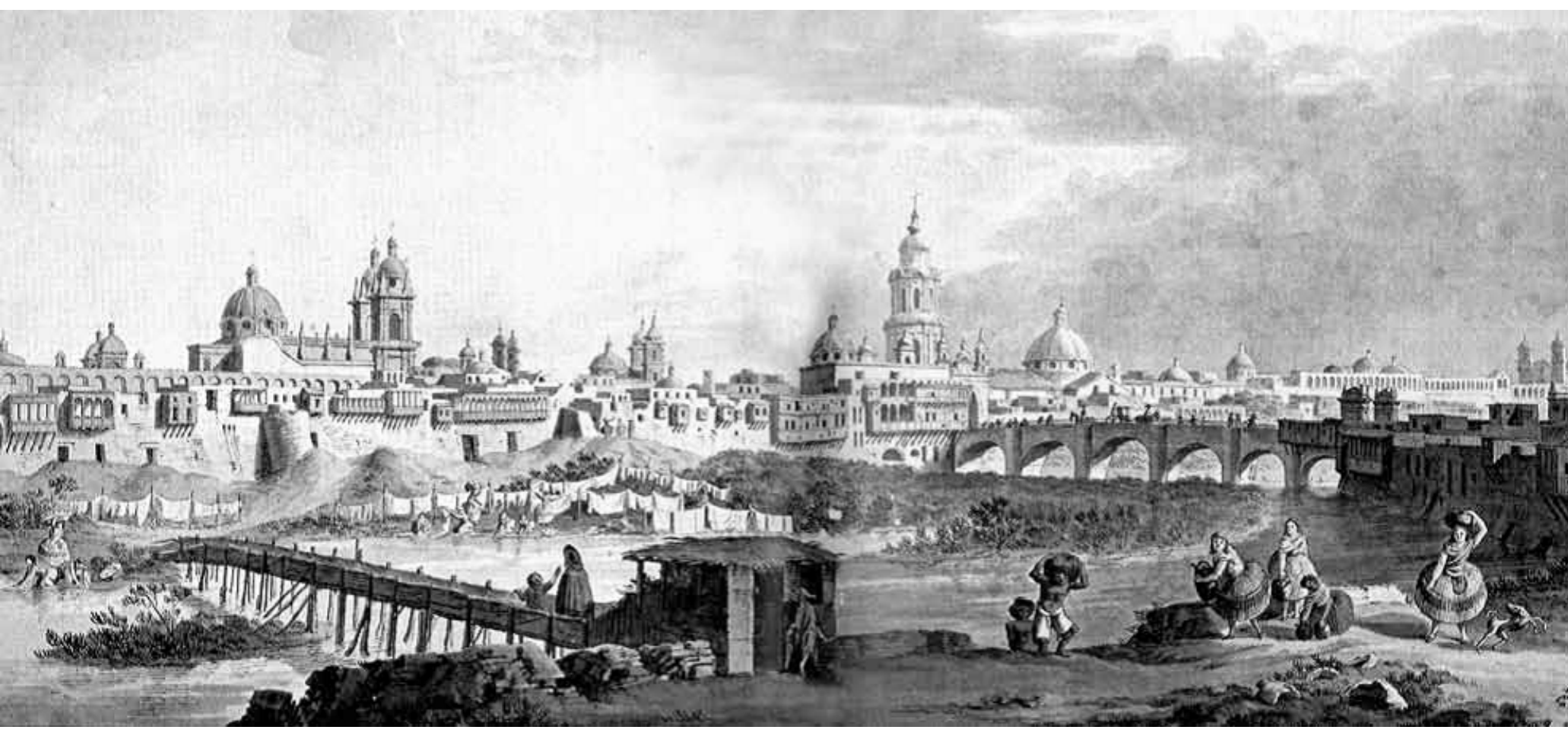

El contrato fue realizado entre Juan José Belzunce, a quien Landaburu le había otorgado poder el 9 de febrero del mismo año para que lo represente, y el virrey. El sitio escogido fue $\mathrm{Acho}^{2}$. Se estipuló que se correrían toros ocho veces al año; además, que la plaza estaría bajo su posesión por 129 años, luego de los cuales pasaría a manos del Gobierno.

La clara afición taurina de Landaburu y el cargo de alcalde de la ciudad, que ocupó en 1766, permitieron que la plaza sea terminada en solo seis meses, sin ir esto en detrimento de lo sólido y firme de su construcción. La misma fue encargada al arquitecto Cristóbal de Vargas, uno de los de mayor prestigio en Lima (Miró Quesada, 1997). El monumento no tenía nada que envidiar a las que había en Pamplona (1764) y Madrid (1754), con las que guardaba muchas similitudes, además de tener el plus de ser la primera de América y la tercera más antigua del mundo. En ella se presentaron los más importantes toreros a nivel mundial, prácticamente todos españoles, quienes dejaron huella y rastro de su paso por ese lugar.

El caso de la Plaza de Toros de Acho se ajusta a la definición brindada en la ya mencionada Carta de Venecia, que indica que el monumento histórico comprende la creación arquitectónica aislada, así como el conjunto urbano que da testimonio de una civilización particular, de una evolución significativa, o de un acontecimiento histórico: el día de inauguración del coso, la ciudad se llenó de júbilo. No había casi persona alguna que se resistiera a conocer sus instalaciones, novedosas para la época, ni a contemplar las jornadas taurinas que allí tomaban un mayor grado de profesionalización. Cabe
Figura 1. Lima desde las inmediaciones de la Plaza de Toros

Fuente: Brambilla, F. (finales del siglo XVIII). Fundación Museo Naval. Lima desde las inmediaciones de la Plaza de Toros. Recuperado de https:// www.google.com/culturalinstitute/ asset-viewer/vista-de-lima-desde-lasinmediaciones-de-la-plaza-de-toros/ QgF8YMvslt3X9w?hl=en
2. La palabra original Ilevaba la consonante H al inicio: 'Hacho'. "Se desconoce el momento exacto en que la perdió, pero, más allá de eso, es de precisar que el término es de origen arábigo y era usado para las ciudades españolas que presentaban un lugar eminente o levantado, o para los pueblos cercanos a la costa desde donde se vislumbraba el mar" (Bromley, 2005, p. 55). En tiempos coloniales desde ese lugar se podía visualizar el océano Pacífico; hoy en día esto es imposible. 
mencionar que en la década de los 90 del siglo pasado, el destacado investigador Aurelio Miró Quesada halló en la Biblioteca Nacional de Santiago de Chile, en la sección Diego Barros Arana, en un tomo de miscelánea encuadernado, en un pergamino con el título 'Folletos de papeles', el impreso titulado "Relación de toros", que consta de dieciséis páginas, y en el que se señala el año de construcción de la plaza y su inauguración.

La edificación del inmueble no fue un hecho aislado; estuvo acompañada de la formación de otros espacios que, afortunadamente para la historia de Lima, aún se mantienen en pie, pese a los embates de la naturaleza y del hombre: el Paseo de Aguas (1770) y la alameda de Acho (1773) ${ }^{3}$. Ambos espacios contribuyeron a que esa zona del Rímac se convirtiera en un importante espacio de socialización y entretenimiento. A ello habría que sumar la coexistencia con las populares casas de juego. Precisamente, abrir una casa de juego alrededor o junto a la Plaza de Toros era un negocio por demás rentable. La gente no solo tenía la opción de entretenerse con la lid de toros, había otra alternativa para aquellos que no llegaban a entrar al coso, para quienes querían seguir divirtiéndose luego de acabada la jornada taurina o, simplemente, para aquellos que preferían los juegos. Así lo constatan las diversas solicitudes para abrir casas de juego en la zona de Acho. De la misma manera, para completar el grado de socialización del espacio, no podía faltar la presencia de otros establecimientos públicos como los tambos y las pulperías, que hacían de este un lugar comercial en el que la gente podía adquirir productos alimenticios y bebidas, aparte de la variedad de entretenimientos que se les ofrecía para pasar un buen rato. Finalmente, en esta descripción no podía quedar al margen el café, la novedad de finales del siglo XVIII, en cuyo interior también se brindaba medios de entretenimiento ${ }^{4}$. De este modo, la expansión de la ciudad hacia el otro lado del Rímac lo convirtió en un gran escenario de recreación extraurbana (Sáenz Mori, 2007).

El conjunto de estos espacios, junto a otros de igual trascendencia (la Quinta Presa, la alameda de los Descalzos, la iglesia San Lázaro, la iglesia Nuestra Señora de Copacabana, por mencionar los más conocidos), recibieron un merecido reconocimiento en 1991 al ser nombrados Patrimonio Cultural de la Humanidad, como parte integrante del Centro Histórico de Lima, al que la UNESCO otorgaba la categoría por ser un ejemplo eminentemente representativo de un tipo de construcción, o de conjunto arquitectónico o tecnológico. Además, el Rímac posee, según el último registro del Ministerio de Cultura, 82 monumentos, una zona ambiental y siete Ambientes Urbanos Monumentales.

En cuanto a la Plaza de Acho, los responsables de la construcción del monumento fueron el alarife Ventura Coco y el maestro director de la obra Cristóbal de Vargas. Ellos la reconocieron, midieron y tasaron en 1767, nuevamente en 1769 , y de manera definitiva en 1776. En su dictamen final, estipularon que Landaburu gastó 107'627 pesos, y un real y medio (Miró Quesada, 1997).

Luego de la muerte de su fundador, la plaza quedó en manos de su esposa Mariana Belzunce, quien, a su vez, antes de su fallecimiento, dio en herencia el manejo del coso al hijo de ambos, Leocadio Landaburu y Belzunce. Sin embargo, Leocadio murió al poco tiempo, por lo que su albacea y tenedor de bienes, el ilustrado Hipólito Unanue, se encargó de la administración. A los pocos años Unanue tomó la decisión de poner en venta pública la Plaza de Acho, por lo que pasó un expediente al virrey Fernando de Abascal comunicándole su deseo de cumplir la voluntad del difunto Leocadio de rematar la plaza por los años que aún la tenía en concesión. Así, la plaza fue trasladada el 4 de octubre de 1817 al Hospicio de Pobres de Lima por los 78 años que restaba cumplir del contrato.

\footnotetext{
3. Bassi y Zavala (2014) apuntan que, con la construcción de la Plaza de Toros, la alameda de Acho se convirtió en un nuevo eje de expansión urbana, y se consolidó el tejido urbano a su alrededor.

4. No obstante, acceder a la plaza era un poco complicado. El único puente permanente que permitía conectarla con el centro de la ciudad era el puente Amaya, que ahora es el llamado puente Balta (Mariátegui, 1956).
} 


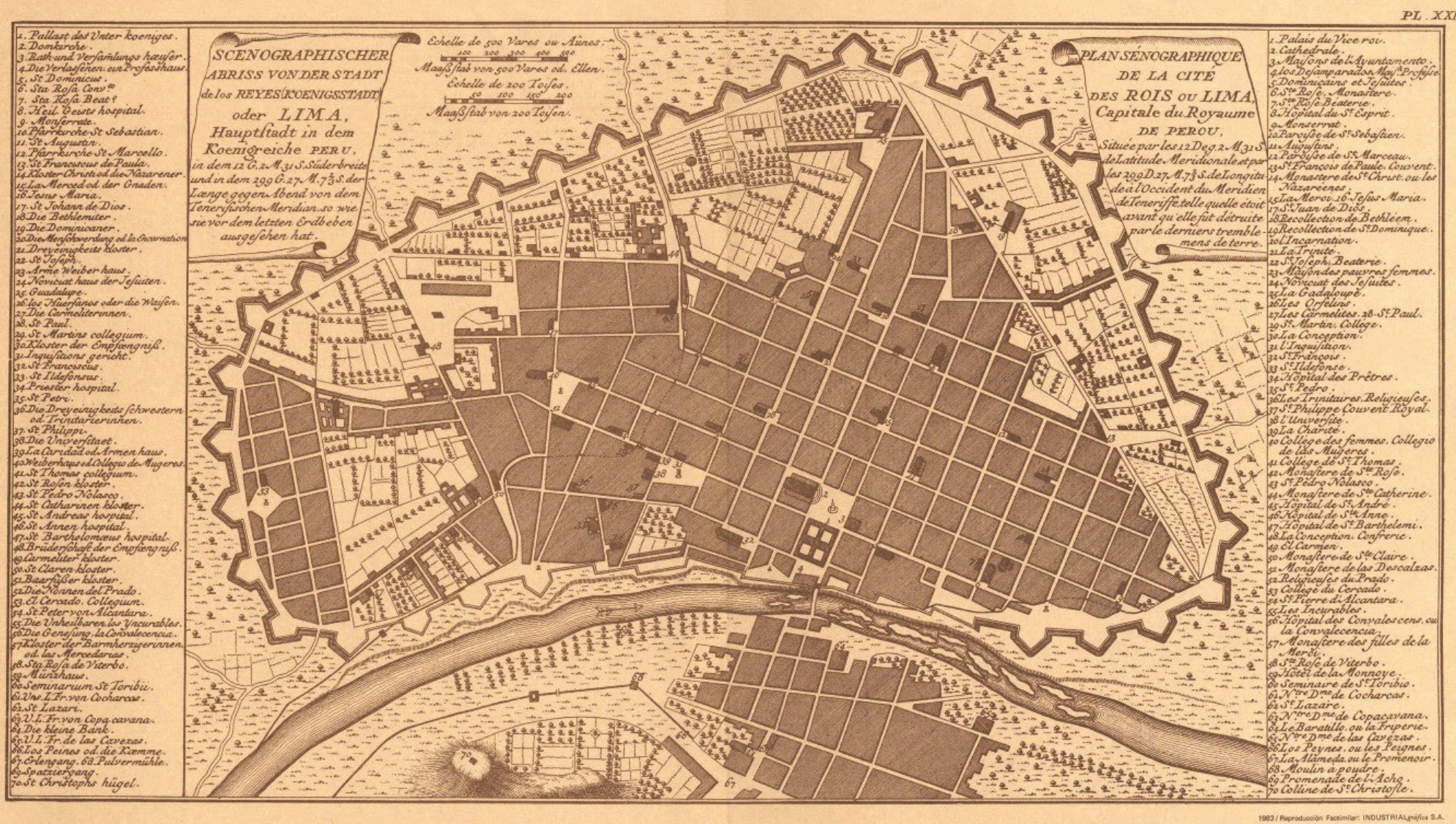

Luego de la Independencia, el libertador José de San Martín tomó la decisión de manejar el coso directamente. El 1 de diciembre de 1821, el marqués de Montemira, por orden del protector, entró en posesión de la plaza, acordándose que el Gobierno utilizaría la ganancia de las entradas en beneficio del ejército libertador, disposición que continuó hasta fines de 1826, cuando finalmente fue devuelta a su legítimo dueño, el Hospicio de Pobres (Garland, 1948). Posteriormente, en 1866 pasó a ser regentado por la Sociedad de Beneficencia Pública de Lima, la cual cada año pone en remate la organización de las tradicionales corridas taurinas que se celebran de manera ininterrumpida hasta el día de hoy.

\section{Reforma Urbana y Estilo Arquitectónico}

Antes de analizar el estilo arquitectónico, es necesario observar la morfología de la ciudad diez años antes del coso y su proceso de transformación urbana. En el plano de la Figura 2, se aprecia las murallas y, fuera de ellas, las extensas zonas rurales que en porcentaje eran mucho mayores que la antigua Lima cuadrada. La figura brinda un acercamiento a la zona que ocuparía pocos años después el coso, lo cual provocó la aceleración del proceso de urbanización del lugar mediante la edificación de casas, establecimientos públicos y espacios de recreación.

La edificación arquitectónica de la actual Plaza de Acho a mediados del siglo XVIII es el resultado de una serie de factores, los cuales se acentuaron tras el devastador terremoto que sacudió la ciudad el 28 de octubre de 1746, pues Lima fue reconstruida de los escombros bajo nuevos patrones estilísticos y modernas técnicas de edificación europea occidental.
Figura 2. Plano de Lima 1756

Fuente: Gunther, J. (1983). Plano de Lima 1756. Elaborado por el geógrafo francés Jacobo Nicolás Bellín. 
Los edificios se reconstruyeron y los nuevos espacios se crearon partiendo de la lógica de modificar algunos patrones clásicos incompatibles con las técnicas sofisticadas que se empezó a adoptar. Según Charles Walker, "la reconstrucción cambió la arquitectura de Lima y aceleró la transición del barroco al neoclásico. Altares, fachadas y edificios fueron demolidos y reemplazados a menudo con estructuras neoclásicas" (2012, pp. 140-141). Además, como bien sustenta Sáenz Mori (2015), el trazado y el modelo urbano del siglo XVI sufrieron transformaciones que llevaron la ciudad al desorden y al caos para esta fecha; ante ello también era necesario reformar la urbe en términos sociales, es decir, ordenar lo desordenado.

En ese sentido, la edificación de la Plaza de Acho formó parte de la política urbanística borbónica de mediados del siglo XVIII, la misma que consistió en destinar a cada actividad de entretenimiento un recinto especifico (Ramón, 1999), para así empezar a desterrar de los espacios abiertos este y otros divertimentos, como las peleas de gallos, que se realizaban en diferentes ambientes en los que no era posible ejercer control, lo que ocasionaba, como es lógico, estragos para los habitantes colindantes y la sociedad en general. Dicha política de reordenar Lima estuvo marcada por la influencia de las ideas ilustradas que llegaron a la capital del Virreinato con el virrey Amat y Junient como uno de sus principales representantes. Los funcionarios progresistas tomaron nota de los trastornos cotidianos que propiciaba el desorden de la urbe, y empezaron a aplicar novedosas ideas para racionalizar lo que hasta entonces se había desarrollado espontánea y desordenadamente. Se tomaron medidas de diverso alcance para mejorar el aspecto y el funcionamiento de la ciudad (Romero, 1976). Para tal cometido, la corrida de toros debía de ser reformada y ordenada.

Respecto a la composición arquitectónica del coso, esta fue pensada de acuerdo al estilo mudéjar. El término'mudéjar'es utilizado para referirse a los musulmanes de los reinos hispanos medievales a quienes, tras la conquista de su territorio, se les permitió quedarse en su lugar de residencia, bajo determinadas condiciones: a cambio de un impuesto, podían conservar su religión, costumbres y un estatus jurídico propio (Romón, 2008). Es así que el estilo tiene su origen en los reinos cristianos de la península lbérica que mezclaron sus técnicas constructivas con las de los musulmanes residentes. Por lo tanto, el arte mudéjar es un fenómeno exclusivamente hispánico, que tuvo lugar entre los siglos XII y XVI, a partir de la mixtificación de las corrientes artísticas cristianas (románicas, góticas y renacentistas) y musulmanas de la época. Se trató de la asimilación de lo árabe en un contexto absolutamente español, por lo que al darse en el siglo XVI el descubrimiento del continente americano y su posterior colonización, este movimiento artístico se extendió hasta principios del siglo XIX en las colonias americanas bajo la denominación 'arte colonial' (Romón, 2008).

La arquitectura mudéjar se caracterizó por ser fundamentalmente decorativa, e introducir nuevas soluciones, como el uso de materiales blandos y baratos como ladrillo, yeso y barro vidriado. En España existe una gran cantidad de casos donde se combinan partes construidas con ladrillo y otras con piedra, tanto sillería como mampuesto (Romón, 2008). Este estilo único e irrepetible le permitió ser declarado Patrimonio de la Humanidad por la UNESCO debido a la originalidad de los monumentos arquitectónicos en que se manifiesta.

En Lima el arte mudéjar mantuvo sus características con pequeñas derivaciones, pues el acceso a los materiales tradicionales no siempre era fácil. Por la misma geografía, así como por otros patrones arquitectónicos que también aquí se establecieron, los albañiles emplearon ligeras modificaciones. La historiadora Lucía Aragón sostiene lo siguiente:

El uso de la madera (principalmente nogal, ébano y ciprés) ha sido uno de los elementos más notables de la arquitectura mudéjar en América. Las techumbres de madera y decoración de techos (alfarjes, armaduras de lacerías, artesonados) las tuvieron la mayoría de las iglesias de Lima colonial. Ejemplos de notables techumbres mudéjares que hasta hoy subsisten son el 


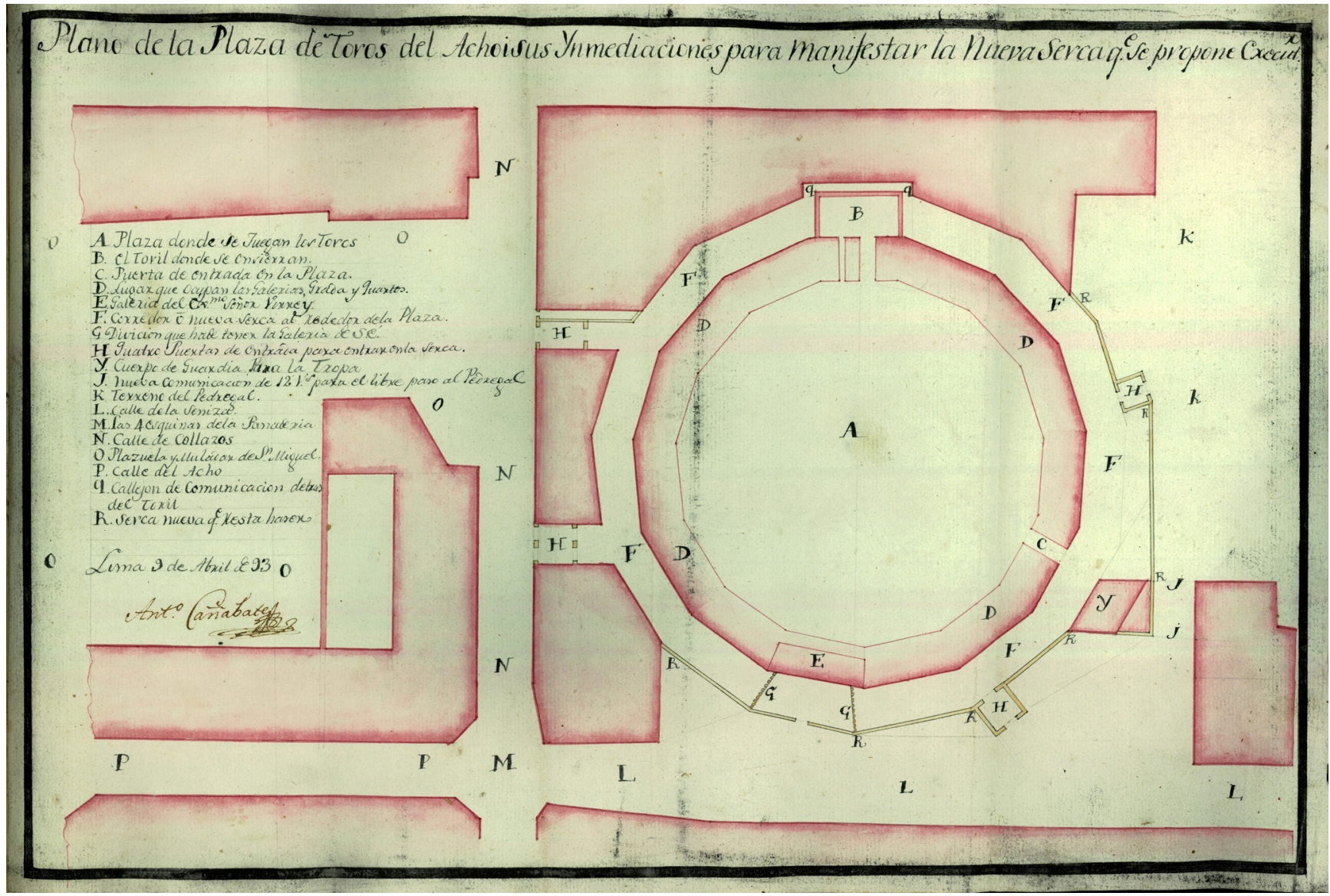

Convento e Iglesia de Santo Domingo, el más antiguo de Lima, que muestra en su portería un precioso techo mudéjar del siglo XVI y en su biblioteca un lujoso techo de artesonado morisco. Así también el Convento de San Francisco, considerado uno de los más hermosos de la ciudad, contiene estos motivos en la cúpula de la escalera del Convento; en la portería, donde se observan tres vanos de curvas mudéjares; en la iglesia, donde los muros, los pilares y las bóvedas están adornados con grecas y lacerías marrocas; y en el claustro, que cuenta con una amplia arquería con azulejos y artesonados mudéjares. (2010, p. 7)

Paralela a la importancia histórica del coso, está la importancia de representar un estilo que en España es patrimonio cultural. De tal modo, no basta con una declaratoria de Monumento Nacional a su favor; hace falta una política cultural de puesta en valor que propicie reconocer realmente los elementos que motivaron que sea declarado patrimonio en 1967. Como proponen Felipe Boado y David Barreiro, "la razón de ser del patrimonio no se agota en sí misma, del mismo modo que el patrimonio no se constituye por sí mismo. Depende de instancias externas a él (los agentes de patrimonialización) que lo convierten en patrimonio al significarlo y valorizarlo" $(2103$, p. 7). Para ello, es preciso sensibilizar a la sociedad respecto de la carga simbólica que encierra y que es parte integral de nuestro acervo cultural.

\section{Cambios Arquitectónicos}

Como ya se mencionó anteriormente, la construcción de la plaza estuvo relacionada con la reforma urbana de mediados el siglo XVIII. Luego fue intervenida en tres oportunidades (1865, 1944 y 1961), por motivo de refacciones para ampliar el aforo de asistentes.
Figura 3. Plano de la Plaza de Toros en 1792

Fuente. Archivo General de la Nación. Superior Gobierno, 1792. 
devenir Vol. 2, N4, JULIO - DICIEMBRE 2015, Pp. 91-103 - Estudios I ISSN 2312-7570

UNIVERSIDAD NACIONAL DE INGENIERÍA, LIMA

Figura 4. Figura de la Plaza de Toros a mediados del siglo XIX

Fuente: Fuentes, M. (1866). El ejército peruano realizando el tradicional despejo, p. 435

Figura 5. Visita general de Lima (1865)

Fuente: Paz Soldán, M. (1865). Visita general de Lima. Map Collection David Rumsey. Recuperado de http://www. davidrumsey.com
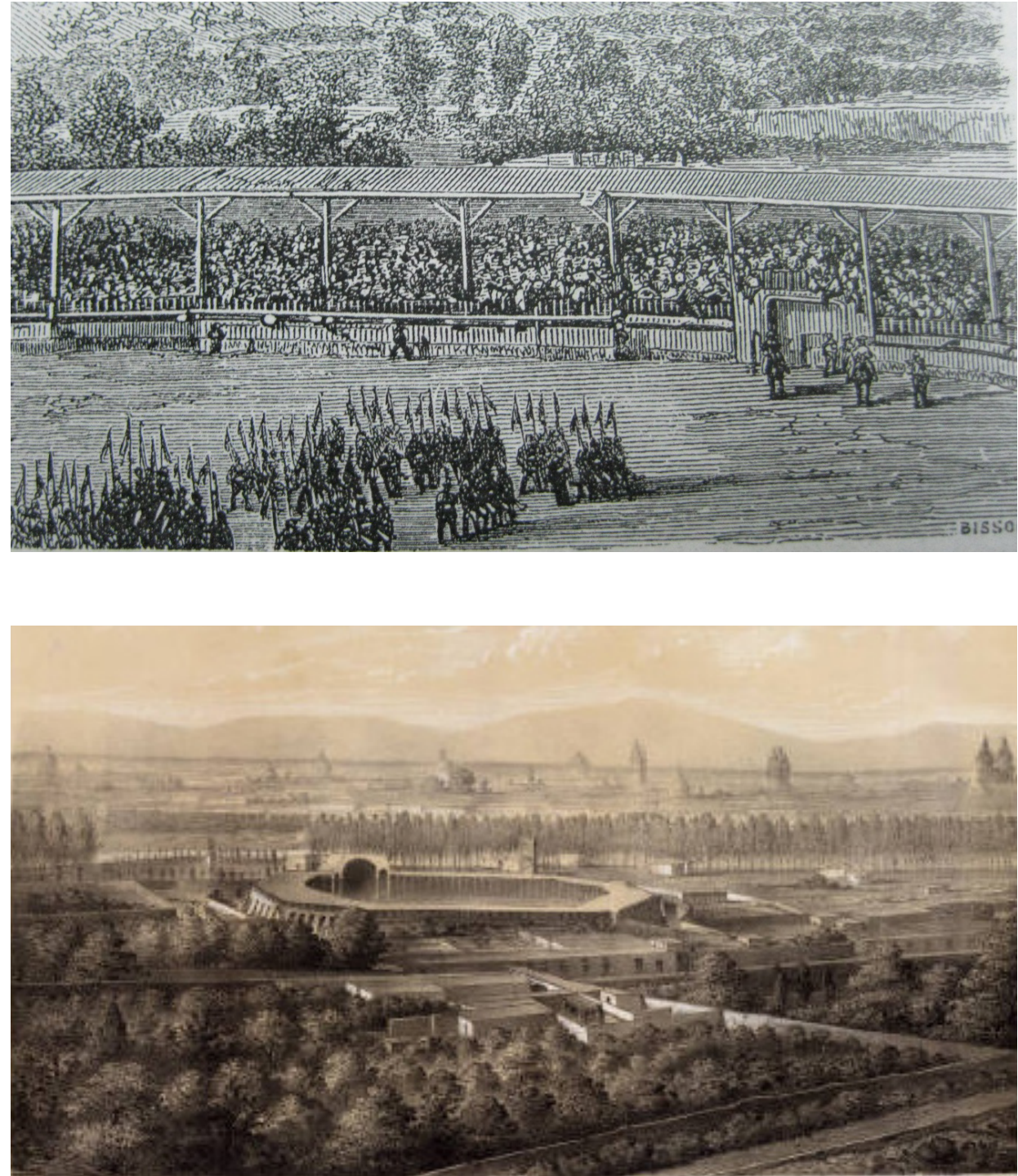

Lamentablemente, no llegó a ser retratada en el momento de su edificación, cuando fue inaugurada, ni en sus primeros años. La primera referencia conocida data de 1792. En ese año la asentista Mariana Belzunce solicitó al virrey Francisco de Taboada licencia para construir un cerco alrededor de la plaza, debido a los constantes perjuicios que sucedían durante las corridas, como los abusos y robos. El 19 de diciembre, mediante un superior decreto, el virrey otorgó licencia para que se construya el cerco. Gracias a este primer plano, es posible saber que estaba rodeada por el lado derecho por el terreno del pedregal, por el izquierdo por la calle del Collazos y por la parte inferior por la calle de la Seniza, la misma que conectaba con la calle de Acho. Juan Bromley añade que al frente estaba la plazuela de Otero (2005) (Figura 3).

Posteriormente, a mediados del siglo XIX, se publica el texto de Manuel Atanasio Fuentes titulado Estadística general de Lima (1866), en el cual realiza una interesante descripción e imagen de la plaza. Para esta época la plaza aún poseía su forma poligonal de "quince lados que miden entre todos doscientas noventa y tres y media varas. El diámetro, considerado de la galería del gobierno hasta el toril es de 94 1 1 varas. Ca- 
ben cómodamente 8691 personas, llegando hasta 10,000 este número en los días de mucha concurrencia" (1866, p. 434). Manifiesta, además, que cuando la plaza estaba desolada, se podía ver lo repugnante, ruinoso y desaseado de su estado. Sin embargo, este puede haber sido un comentario motivado por su clara oposición a las jornadas taurinas, aunque tenía razón al criticar el material de los asientos por ser de tabla, sin nada sobre ellos que pudiera hacerlos blandos y cómodos. Asimismo, afirma que el techo era "una puerca ramada de esteras que amenaza ruina" (1866, p. 436), mientras que los bancos de los cuartos eran de tierra y ladrillo (Figura 4).

Por su parte, el historiador Mariano Felipe Paz Soldán había publicado un año antes su libro Geografía de Perú (1865), en el que brinda una mirada externa de la plaza. En ella se observa la poca altura que tenía y el tipo de material del que estaba cubierta, así como el hecho de que estaba rodeada por frondosos árboles al pie del cerro San Cristóbal. La gran cantidad de vegetación favorecía a la ciudad estética, ambiental y socialmente, pues resultaba beneficioso para la salud de los vecinos y para aquellos que la visitaban (Figura 5).

La siguiente imagen disponible corresponde a mediados del siglo XX: es una vista aérea de la plaza luego de sus remodelaciones (Figura 6). Al ejecutarse la transformación total de su estructura, se le dio una forma circular, se construyó tribunas de cemento y se aumentó su aforo a 13,300 espectadores. Se prolongó bajo el nivel del piso para aprovechar la amplitud del antiguo ruedo, que quedó así reducido. El techo sostenido por columnas quedó como un vistoso adorno arquitectónico en la parte alta de los tendidos. Además, el centro del ruedo se redujo de 90 a 60 metros de diámetro. Desde el cerro San Cristóbal, se aprecia la figura geométrica que tiene y los demás inmuebles históricos que la acompañan.

La última imagen es una vista satelital (Figura 7). En esta se puede observar que el poco desarrollo urbanístico y el aumento demográfico son lo característico del lugar. El acceso a la plaza es por medio de la avenida Abancay, por la avenida Acho o por la Vía de Evitamiento. Durante el mes de octubre, los aficionados taurinos ocupan las inmediaciones para celebrar cada año la Feria del Señor de los Milagros, costumbre establecida desde el 12 de octubre de 1946 en conmemoración del día del descubrimiento de América.
Figura 6. Vista aérea de la plaza, 1962

Fuente: Recuperado de http://www. achotoros.dnet.com.pe/toronet/acho/ achohistoria.html

Figura 7. Vista satelital de la Plaza de Acho

Fuente: Google Earth. Vista satelital de la Plaza de Acho. Recuperado de http://plazadeacho.galeon.com/historia.html, 2010.
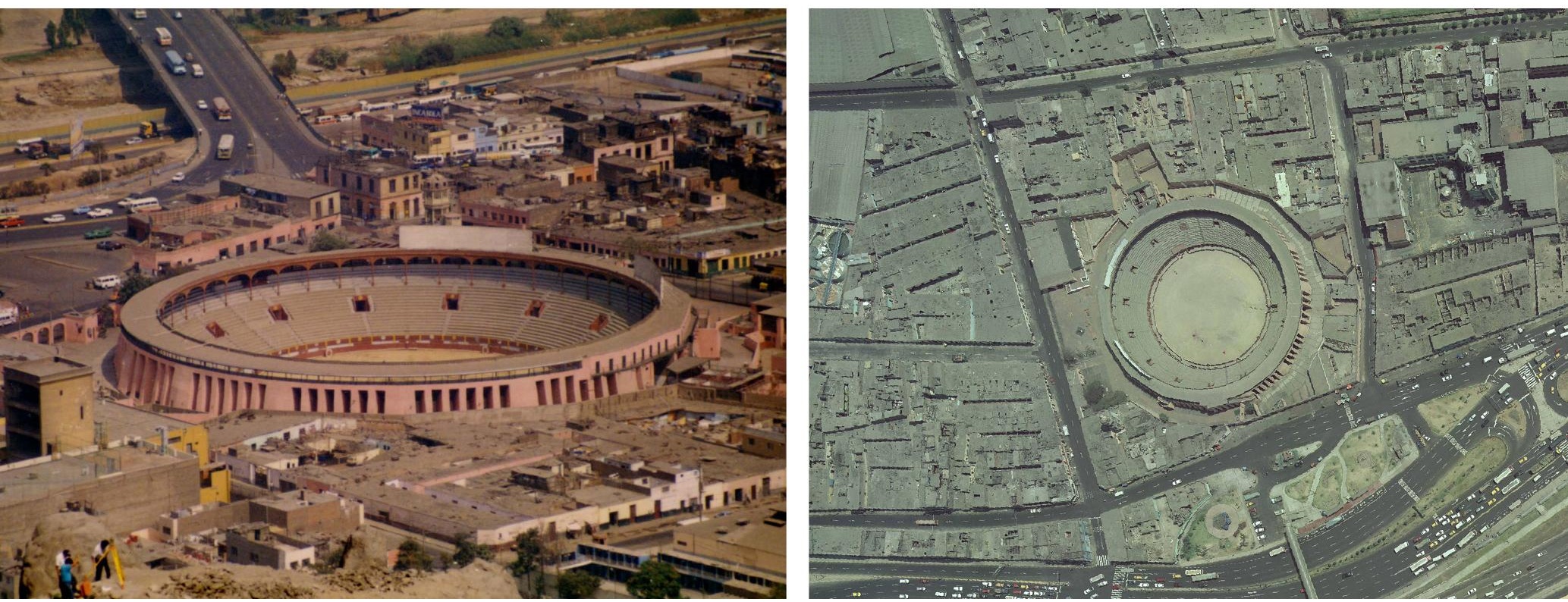


\section{Las Corridas de Toros}

Es imposible dejar de mencionar el espectáculo que albergó en su interior la plaza: las corridas de toros. Estas son una herencia española que se mantuvo aun luego de la proclamación de la Independencia en 1821, a pesar del surgimiento de una creciente oposición que empezó a cuestionar esta costumbre colonial.

Las primeras corridas de toros en Lima corresponden a pocos años después de fundada la ciudad. Para el tradicionalista Ricardo Palma, el lunes 29 de marzo de 1540, en la Plaza Mayor, se realizó la primera lidia de toros, presidida por Francisco Pizarro, con motivo de la celebración de óleos del arzobispo fray Vicente Valverde. Inicialmente las corridas tenían un sentido elitista: solo los españoles podían torear, mientras que el resto de la población cumplía un rol secundario de mero espectador o compañía. Al ser las corridas una forma de manifestación de las jerarquías sociales, considerando que se organizaban para conmemorar el triunfo español de la conquista y la fundación de Lima, fueron una expresión del nuevo escenario que se desarrollaba y sus protagonistas: por un lado el español conquistador y por el otro el indígena conquistado.

Era recurrente que se organizaran lidias para conmemorar diferentes celebraciones: la llegada de un nuevo virrey, el nacimiento de un príncipe, las exequias del rey o la coronación de un nuevo monarca, entre otras. Justamente, en 1555 el cabildo limeño señaló cuatro días para la fiesta taurina: el 6 de enero, Día de los Reyes, aniversario de la fundación o de la epifanía; el 24 de junio, Día de San Juan Bautista; el 25 de julio, Día de Santiago Apóstol, patrón de España; y el 15 de agosto, Día de Nuestra Señora de la Asunción. Naturalmente, las corridas que tenían lugar eran más que las formalmente establecidas.

El lugar idóneo y central donde se llevaban a cabo era la Plaza Mayor, por ser sede del poder regio español, y, en menor grado, también en las plazuelas de San Francisco y de Santa Ana (Durán, 1994). No obstante, en el siglo XVIII el sentido elitista de las corridas cambió para convertirse en una diversión completamente popular.

Desde muy temprano se hizo notoria la gran pasión e inquietud que existía por los toros. Los días dedicados a las corridas absorbían por entero las demás actividades humanas. La religión, la justicia, el comercio, la industria, el orden familiar, la economía y el trabajo, todo se postergaba ante este espectáculo. El día más controversial era el domingo, en especial luego de la erección de la Plaza de Toros de Acho en 1766, pues se llegó al punto de prescindir de la obligación cumbre de oír misa ese día por acudir desde las primeras horas de la mañana a la plaza para ocupar un asiento. Para conciliar la devoción religiosa con el culto social a los toros, se tuvo que trasladar el espectáculo a los lunes (Valega, 1939).

El historiador López Martínez menciona que la nobleza limeña y peruana, en general, gastaba verdaderas fortunas en la crianza y adiestramiento de caballos para capear en Acho: "Ellos mismos solían actuar en corridas benéficas y rivalizaban para que los capeadores profesionales -casi todos negros- utilizaran sus cabalgaduras para alcanzar éxito de apoteosis" (2005, p. 47). Precisamente, uno de los principales atractivos era el toreo a caballo. Ismael Portal, confeso aficionado a las lidias, afirmaba que "una corrida sin capas de a caballo sería imposible, pues no solo era la costumbre sino también la necesidad, especialmente al tratarse de bichos poderosos y de pies, reclamaba la presencia de cuando menos dos de ellas" (1892, p. 18). El capeo a caballo nació en Lima y se propagó pronto al resto del virreinato. Fue el ingrediente que caracterizó a las corridas que allí se realizaban, frente a las que se daban en España. Por esa razón, se le consideró el toreo nacional (Portal, 1892). Antonio Garland añade que la afición era tan considerable "que nos dimos el lujo de crear una suerte de exclusiva invención nacional que perduró hasta comienzos del siglo XX" (1948, p. 27). 
En el siglo XVIII esta fiesta perdió su significado inicial, el ser un medio de legitimación del orden social, del dominio del español sobre el indígena y su carácter caballeresco-guerrero, a causa de que cayó en manos de la población. No obstante, ello no significó la total disociación de la nobleza con las corridas, pues aún las seguían frecuentando, aunque de forma distinta, ya no como los actores principales que se echaban al ruedo, sino como espectadores privilegiados, quienes desde lugares preferenciales observaban la fiesta taurina. José Valega está en lo correcto cuando sostiene que "la fiesta taurina era una fiesta singular que atraía con igual intensidad a la más alta nobleza y al último gañán del huerto arrabalero; a la dama del linaje sonoro y a la ínfima esclava del menor de los burgueses" (1939, p. 353).

\section{La Plaza de Toros en la Actualidad}

Desde su fundación la plaza ha tenido un solo uso: las corridas de toros. En el contrato realizado entre su fundador Agustín de Landaburu, y el virrey Amat y Junient, se dejaba en claro cuántas corridas debían de realizarse al año, pero no qué pasaba con el resto de días, en los que no había corridas. La plaza lucía desolada y olvidada, como si fuera un espacio más dentro de la ciudad. Eventualmente, dependiendo de las circunstancias, se realizaban corridas forzosas, por ejemplo, las realizadas a favor de la causa realista durante el proceso independentista o las celebradas con motivo de la guerra con Chile.

Este uso exclusivo es una de las causas de la situación actual del coso. En pleno siglo XXI las corridas ya no son como antes, en primer lugar debido al cambio de la fecha de su celebración de los primeros meses del año al mes de octubre, con motivo de la feria del Señor de los Milagros. No cabe duda de que las corridas siguen acaparando la atracción de propios y extraños, ni de que la motivación es la misma que hace más de 250 años, presenciar únicamente las jornadas taurinas. Sin embargo, sus usos podrían ser más diversos.

Un intento de remediar la actual situación fue la creación del museo taurino en las inmediaciones de la plaza, el mismo que hasta el momento ha calado poco en el sentir y curiosidad de las personas que transitan el lugar, lo cual es comprensible, pues actualmente es un albur recorrer el jirón Hualgayoc debido a la escasa seguridad de la zona. A ello se suma la imagen negativa que recae sobre las corridas en sí, dado que son consideradas por muchos como una forma de crueldad animal.

Una adecuada política cultural debería empezar por mejorar la imagen de esta zona de la ciudad de Lima, pues la falta de seguridad es el principal problema que ahuyenta a los visitantes. En ese sentido, la inversión privada también entra en juego. Felizmente hay empresas o agrupaciones a las que les interesa invertir en la puesta en valor del patrimonio cultural. Sin embargo, tal intención no es desinteresada. Así un sector de la amplia zona que ocupa la plaza puede ser condicionada para ofrecer otros productos, más allá de lo cultural, sin que ello vaya en desmedro del fin principal, que es difundir la cultura.

\section{Reflexiones Finales}

El presente trabajo ha intentado poner de relieve la importancia histórica del coso más antiguo de Sudamérica, su estilo arquitectónico y la reforma urbana de la que fue parte, en contraste con el estado en que se encuentra. El poco interés por restaurar este monumento histórico es notorio. Más allá de las pequeñas intervenciones ejecutadas, ya sea para ampliar su aforo, para celebrar su centenario o por orden expresa de Defensa Civil por razones de seguridad, hasta el momento no se ha realizado ningún tipo de intervención para recuperarlo. La tarea de poner en valor la Plaza de Acho es una obligación tanto de las autoridades competentes como de los mismos ciudadanos. 
Como bien sustentan Felipe Boado y David Barreiro, la razón de ser del patrimonio es la siguiente:

Es el resultado de actos de valoración y estima que permiten reconocer al patrimonio como algo propio o reconocible por ciertos sectores, cuando no por la totalidad de una sociedad. Pero eso quiere específicamente decir que el patrimonio no se puede separar de la estima que los pueblos, comunidades e individuos sienten por él, y por lo tanto su protección, gestión y conservación no se resolverá debidamente sin tener en cuenta esta valoración. Sin un acto inicial de aprecio el patrimonio no llega a ser tal; pero tampoco se puede conservar y mantener sin el aprecio posterior. Lo que no se aprecia, deja de ser valorado como patrimonio... (2013, p. 11)

Sin embargo, existen aspectos positivos. Cabe resaltar el impulso que está intentando dar el Patronato del Rímac al rescate, no solo de la Plaza de Acho, sino también de los inmuebles que conforman esa parte histórica del distrito. Resaltando la tradición y cultura provenientes del período colonial, mediante la recuperación, conservación y puesta en valor de los monumentos históricos de la época, se busca aportar al desarrollo y relanzar la riqueza cultural del Rímac.

En ese sentido hay un punto importante que mencionar. En líneas anteriores se ha mencionado el papel que tiene en el rescate del patrimonio la inversión privada, cuando ello se hace de manera seria y comprometida. El caso de la empresa ecuatoriana CITOLUSA es un ejemplo de una inadecuada gestión. Esta empresa obtuvo la concesión del coso en el 2014 por seis años, cuyo objetivo a corto plazo era reimpulsarlo como un importante centro cultural y de espectáculos. No obstante, después de un poco más de un año y medio, la empresa la abandonó sin haber realizado su necesaria restauración y dejó en la incertidumbre las celebraciones a realizarse por sus 250 años, bajo el argumento que durante el corto tiempo que estuvo dirigiéndola solo obtuvo pérdidas económicas.

Se necesita una gestión cultural que empiece por rescatar la plaza y por brindarle el espacio que merece, una gestión que apueste por proteger, difundir y valorar parte de nuestra historia. No se debe esperar que ocurra algún desastre, producto de la fuerza natural o humana, para recién tomar las medidas oportunas para su revaloración patrimonial. Es por ello que resulta paradójico que lo cultural no vaya acompañado del progreso social. Hoy en día se habla más del hacinamiento, la tugurización, la delincuencia y la falta de seguridad que padece la población rimense, que de todo el vestigio monumental que acoge. Recordemos que la zona en que se ubica la Plaza de Acho forma parte del centro histórico de Lima, que además es Patrimonio Cultural de la Humanidad, a pesar de que su condición actual no esté a la altura de tal rótulo.

No se trata de cualquier plaza: es la primera que existió en Sudamérica y la tercera en el mundo. A poco de festejar su cuarto de milenio de existencia, es oportuno revalorar su importancia histórica como parte de la cultura milenaria de la antigua Ciudad de los Reyes.

\section{Referencias}

Aragón, I. L. (2010). Arquitectura mudéjar en el Perú. Chasqui. El Correo del Perú. 8 (17), 6-7.

Bassi, G. M. \& Zavala, S. L. (2014). Evolución y desaparición de la alameda de Acho. En Concursos Juan Gunther, pp. 105-157. Lima, Perú: Municipalidad Metropolitana de Lima - Los Portales.

Bromley, J. (2005). Las viejas calles de Lima. Lima, Perú: Gerencia de Educación, Cultura y Deportes, Municipalidad Metropolitana de Lima.

Castillo, J. (2007). El futuro del patrimonio histórico: La patrimonialización del hombre. Revista Electrónica de Patrimonio Histórico, (1), 1-36. Recuperado de http://www.revistadepatrimonio.es/revistas/numero1/concepto/estudios/articulo.php 
Criado-Boado, F. y Barreiro, D. (2013). El patrimonio era otra cosa. Estudios Atacameños. Arqueología y Antropología Surandinas, (45), 5-18. Recuperado de http://www.scielo.cl/pdf/eatacam/ n45/art02.pdf

Choay, F. (2000). Alegoría do patrimonio. Lisboa, Portugal: Ediçoes.

Durán y Montero, M. A. (1994). Lima en el siglo XVII. Arquitectura, urbanismo y vida cotidiana. SeviIla, España: Diputación Provincial de Sevilla.

Fuentes, M. A. (1866). Estadística general de Lima (2da ed., vol. 1). París, Francia: Tipografía de A. D. Lainé y .J. Havard.

Garland, A. (1948). Lima y el toreo. Lima, Perú: Librería Internacional del Perú.

Gunther, J. (1983). Planos de Lima. Lima, Perú: Municipalidad de Lima Metropolitana, Petróleos del Perú.

López, H. (2005). Plaza de Acho. Historia y tradición, 1766-1944. Lima, Perú: Fondo Editorial del Congreso del Perú.

Mariátegui, R. (1956). El Rímac, barrio limeño de abajo del puente. Guía histórica y artística. Lima, Perú: Talleres Gráficos CECIL.

Miró Quesada, A. (1997). Temas taurinos. Lima, Perú: El Comercio.

Paz Soldán, M. F. (1865). Geografía del Perú. París, Francia: Librería de Augusto Durand.

Portal, I. (1892). La fiesta española en el Perú. Lima, Perú: Imprenta de la Escuela de Ingenieros.

Ramón, G. (1999). Urbe y orden: Evidencias del reformismo borbónico en el tejido limeño. En S. O'Phelan (Comp.), El Perú en el siglo XVIII: La era borbónica. Lima, Perú: Instituto Riva Agüero.

Romero, J. L. (1976). Latinoamérica: Las ciudades y las ideas. México: Siglo Veintiuno.

Romón, J. I. (2008). La arquitectura mudéjar: Aglutinante social y expresión del primer estilo español. En Sara M. Saz (Ed.), Acortando distancias: la diseminación del español en el mundo. Actas del XLIII Congreso Internacional de la Asociación Europea de Profesores de Español. Madrid, España: Universidad Nacional de Educación a Distancia.

Sáenz, I. (2015). El damero en discusión: Prácticas espaciales y cartografía urbana en Lima tardo colonial. Terra Brasilis (Nova Série), (4), 1-17. Recuperado de https://terrabrasilis.revues. org/1129

Sáenz, I. (2007). Imágenes ribereñas. El Rímac y el proceso urbano de Lima virreinal (siglos XVI$\mathrm{XIX).} \mathrm{Revista} \mathrm{Lima} \mathrm{CAP,} \mathrm{(7),} \mathrm{20-25.}$

Valega, J. M. (1939). El Virreinato del Perú. Lima, Perú: Imprenta LUX.

Walker, C. (2012). Colonialismo en ruinas. Lima frente al terremoto y tsunami de 1746. Lima, Perú: Instituto de Estudios Peruanos - Instituto Francés de Estudios Andinos. 